ORIGINAL RESEARCH ARTICLE

\title{
Reducing Maternal Mortality by Strengthening Community Maternal Support Systems: Findings from a Qualitative Baseline Study in Northern Nigeria
}

\author{
Ekechi Okereke ${ }^{1 *}$, Susan B. Aradeon ${ }^{2}$, Ibrahim Yisa ${ }^{1}$
}

Abt Associates Nigeria/Partnership for Transforming Health Systems Phase 2 (PATHS2), Abuja Nigeria ${ }^{1}$; Freelance International Consultant (Social and Behavioral Change Communication), Aventura, FL, USA ${ }^{2}$

*For Correspondence: Email: eokereke78@gmail.com; Phone: +234 8038036923

\begin{abstract}
The "three delays model" illustrates how issues around obstetric emergency can lead to maternal deaths. This study applied indepth interviews of key community gatekeepers in 16 rural communities across two states in northern Nigeria to evaluate the presence and functionality of key community maternal support systems for reducing maternal mortality. Findings show that only one out of the 16 communities had all the key support systems. Five rural communities reported that pregnant women have standing permission to visit health facilities during obstetric emergencies. A quarter of the communities reported the presence of transport for maternal emergencies. One rural community each reported the existence of community savings for obstetric emergencies and the presence of blood donor groups. Establishing and/or strengthening community support systems, ensuring citizens are well-informed about maternal danger signs and preparing for safe pregnancies can enable communities overcome the delays and reduce maternal mortality especially in low resource settings. (Afr J Reprod Health 2016 (Special Edition); 20[3]: 159-167).
\end{abstract}

Keywords: Community maternal support systems, 'three delays', maternal mortality, Northern Nigeria

\section{Résumé}

Le modèle des "trois retards" illustre la façon dont les questions autour de l'urgence obstétricale peuvent conduire à des décès maternels. Cette étude s'est servi des entrevues en profondeur des principaux gardiens communautaires dans 16 communautés rurales à travers deux Etats du nord du Nigeria pour évaluer la présence et la fonctionnalité des systèmes de soutien maternels communautaires clés pour réduire la mortalité maternelle. Les résultats montrent que seule une des 16 communautés avait tous les systèmes de soutien essentiels. Cinq communautés rurales ont indiqué que les femmes enceintes ont la permission de visiter les établissements de santé n'importe quand au cours des urgences obstétricales. Un quart des communautés ont signalé la présence de transport pour les urgences maternelles. Chacune des communautés rurales a signalé l'existence d'épargne communautaire pour les urgences obstétricales et la présence de groupes de donneurs de sang. Etablir et / ou renforcer les systèmes de soutien communautaire, assurer que les citoyens sont bien informés sur les signes de danger maternel et la préparation pour les grossesses sans danger peuvent permettre aux communautés à surmonter les retards et réduire la mortalité maternelle en particulier dans les milieux à faibles ressources. (Afr J Reprod Health 2016 (Edition Spéciale); 20[3]: 159-167).

Mots-clés: systèmes de soutien maternelle communautaire, «trois retards», mortalité maternelle, nord du Nigeria.

\section{Introduction}

Many developing countries were unable to attain the Millennium Development Goals (MDGs) but the Sustainable Development Goals (SDGs) present new opportunities. Over the years, numerous strategies and interventions have been proposed and implemented for reducing maternal mortality. Evidence suggests that increasing access to emergency obstetric care will significantly reduce maternal mortality ${ }^{1,2}$. There are a number of factors that could affect the decision by pregnant women and their families to 'seek', 'reach' and 'receive' proper health services when experiencing complications associated with pregnancy, delivery and the postpartum period. These include lack of awareness about maternal danger signs, unpreparedness for maternal emergencies, economic factors, socio-cultural norms as well as the distance between health facilities and the homes of pregnant women, particularly within rural communities ${ }^{2,3,4}$.

The "three delays model" identifies delays that have direct consequences for the life of both the prospective mother and child ${ }^{5}$. This concept suggests that pregnancy-related mortality is 
overwhelmingly due to delays associated with (i) deciding to seek appropriate medical care for an obstetric emergency (ii) reaching an appropriate obstetric facility; and (iii) receiving adequate care once at a health facility ${ }^{5,6,7}$. A study conducted in Nigeria identified delays as being responsible for pregnant women not getting prompt and appropriate services during complications and reported that delays were responsible for about $77.8 \%$ of all maternal deaths in that study ${ }^{8}$. In addition, a retrospective study in Pakistan indicated that $94 \%$ of women included in the study had one or more delays, with $71 \%$ having the first delay, $74 \%$ having the second delay while $48 \%$ experiencing the third delay ${ }^{9}$. These statistics suggest that understanding the three delays, properly designing and implementing interventions and strategies that address these delays will have a significant impact on maternal mortality.

Nigeria is estimated to have a population of over 140 million people ${ }^{10}$. Approximately 31 million women of childbearing age live within the country ${ }^{11}$ and it has been estimated that more than $50 \%$ of all maternal deaths worldwide are attributable to six focal countries including Nigeria $^{12}$. In Nigeria, the maternal mortality ratio (MMR) is higher in the northwest $(1,025$ deaths per 100, 000 live-births) and northeast (1,549 deaths per 100,000 live-births) parts but lower in the southwest (165 deaths per 100,000 live-births) and southeastern parts of the country ${ }^{11,13}$. In addition, the MMR in rural areas (828 deaths per 100,000 live-births) is estimated to be more than twice that in urban areas (351 deaths per 100,000 live-births) across the country ${ }^{11,13}$. These figures highlight the need to address these high maternal mortality rates while paying particular attention to rural northern Nigerian communities.

The first two delays take place in communities, consequently they require community interventions. However, many studies that examine the utilization of reproductive health care services tend to ignore the influence of community attributes and the impact of these on reducing maternal deaths ${ }^{14}$. While the importance of skilled birth delivery and facility-based health services for addressing emergency obstetric complications cannot be ignored, strong evidence also indicates the value of integrating these with community based health interventions to reduce maternal mortality ${ }^{15}$. Costello argues that community based strategies have not been recognized for their true worth in the fight against maternal mortality ${ }^{16}$. This study was carried out in 2012 as part of a baseline assessment for a community-based safe motherhood intervention by the Partnership for Transforming Health Systems Phase 2 (PATHS2). PATHS2 is a health systems strengthening project sponsored by United Kingdom's Department for International Development (DfID) and implemented by a consortium of partners led by Abt Associates. Findings from the quantitative component of the baseline assessment have already been published ${ }^{17}$. This article outlines findings from the qualitative component of the baseline assessment and discusses the implications of strengthening community maternal support systems as a strategy for attaining the SDG-maternal mortality reduction goals.

\section{Methods}

This baseline assessment was undertaken in two PATHS2 supported States within northern Nigeria: Kaduna and Kano States. According to the 2006 Nigerian National Census, Kaduna State has an estimated population of 6,094,506 million and consists of 23 Local Government Areas (LGAs). Kano State has an estimated population of $9,401,288$ with 44 local government areas ${ }^{18}$. Health and demographic reports of Kaduna and Kano States record maternal mortality rates of over 1,000 deaths per 100,000 live births, high total fertility rates of over 7 births per woman and most female teenagers $(<20$ years) have already married and started bearing children ${ }^{19,20}$.

Eight rural communities with populations of about 5,000 each or less were selected as intervention communities for the Safe Motherhood Initiative Demand Side (SMID) intervention within each State by the PATHS2 project. The intervention communities were selected randomly from among a pool/list of rural communities with populations of 5,000 or less within PATHS2 clusters in both States. Within the PATHS2 cluster system, clusters consist of a group of 13 selected health facilities that provide graded levels of emergency and obstetric care as well as referral 
Table 1: Selected Rural Communities in Kano State and Community Maternal Support Systems

\begin{tabular}{|c|c|c|c|c|c|c|}
\hline \multirow[t]{2}{*}{ LGA } & \multirow[t]{2}{*}{ Community } & \multirow{2}{*}{$\begin{array}{l}\text { Estimated } \\
\text { Community } \\
\text { Population }\end{array}$} & \multicolumn{4}{|c|}{ Community maternal support systems established } \\
\hline & & & $\begin{array}{l}\text { Community } \\
\text { savings }\end{array}$ & $\begin{array}{l}\text { Emergency } \\
\text { transport }\end{array}$ & $\begin{array}{l}\text { Blood } \\
\text { donor } \\
\text { groups }\end{array}$ & $\begin{array}{l}\text { Standing permission } \\
\text { within households }\end{array}$ \\
\hline Bichi & Dangawo & 2458 & - & Yes & - & - \\
\hline Bichi & Malamawa & 4009 & - & Yes & - & - \\
\hline Bichi & Shatunbi & 3642 & - & - & - & Yes \\
\hline Kunchi & Yankifi & 5618 & - & - & - & - \\
\hline Kunchi & Sodawa & 2330 & - & - & - & - \\
\hline Tsanyawa & Harbau & 5005 & - & - & - & - \\
\hline Tsanyawa & Yargwanda & 3335 & - & - & - & - \\
\hline Tsanyawa & Majema & 4278 & - & - & - & - \\
\hline
\end{tabular}

Table 2: Selected Rural Communities in Kaduna State and Community Maternal Support Systems

\begin{tabular}{lllcccc}
\hline LGA & Community & $\begin{array}{l}\text { Estimated } \\
\text { Community } \\
\text { Population }\end{array}$ & \multicolumn{3}{l}{ Community maternal support systems established } \\
\cline { 3 - 7 } & & & $\begin{array}{l}\text { Community } \\
\text { savings }\end{array}$ & $\begin{array}{l}\text { Emergency } \\
\text { transport }\end{array}$ & $\begin{array}{l}\text { Blood } \\
\text { donor } \\
\text { groups }\end{array}$ & $\begin{array}{l}\text { Standing permission } \\
\text { within households }\end{array}$ \\
BirninGwari & DawakinBasa & 4212 & Yes & Yes & Yes & Yes \\
BirninGwari & Gwanda & 2251 & - & - & - & - \\
BirninGwari & Ingade & 2331 & - & - & - & Yes \\
BirninGwari & UnguwarDanko & 2621 & - & - & - & - \\
BirninGwari & Tabanni & 2175 & - & - & - & Yes \\
BirninGwari & TasharKeji 1 & 3460 & - & - & - & - \\
BirninGwari & Old Kuyello & 2950 & - & Yes & - & Yes \\
BirninGwari & Dunya & 2100 & - & - & - & \\
\hline
\end{tabular}

services for the purpose of reducing maternal mortality within a population of 500,000 persons. Each cluster is made up of one to four Local Government Areas (LGAs), depending on the LGA's population size. Prior to the start of the SMID intervention in these two States, a baseline assessment was undertaken with a key objective to assess the existence or not and functionality of community maternal support systems for safer pregnancy and delivery outcomes for women of reproductive age. This qualitative study was undertaken in the 16 selected communities between September and October 2012. After pretesting the interview guide, the research team carried out in-depth interviews with community leaders and Imams (religious leaders) within selected intervention communities using the semistructured interview guide. The community leaders and Imams being key gatekeepers were expected to have knowledge of community support systems within their communities. The research participants were assured of the confidentiality of their identities. Informed consent was also obtained from research participants before the interviews commenced. Verbal consent from study participants was regarded as sufficient for respondents to participate and the verbal consents were documented using tape recorders. The study investigators also provided a written statement regarding the research in the form of an information sheet to each of the research participants at the start of the interview. Permission to carry out the study in the selected rural communities was obtained from relevant local government health officials within each state. In addition, the Ministries of Health in Kaduna and Kano states gave ethical approval to conduct the assessment in both states. The interviews were conducted in the local Hausa language. All interviews were subsequently transcribed and translated from Hausa to English language. Using a pre-determined coding framework, coding and thematic analyses were carried out on the qualitative data collected from the baseline 
assessment.

\section{Results}

Table 1 outlines the rural communities selected for the baseline assessment in Kano State, indicating their location i.e. Local Government Area (LGA), estimated populations and the presence or absence of community maternal support systems in these communities. Table 2 highlights the selected rural communities in Kaduna State, indicating their location, estimated populations and the presence or absence of community maternal support systems.

\section{Presence of community savings for obstetric emergencies}

Availability of funds as well as the socioeconomic status of the household of a pregnant woman affects her decision to access health services at a nearby health facility and are strongly associated with the first delay to accessing emergency obstetric health care. All the communities that were assessed within Kano State indicated that there were no specific savings set aside within the community for maternal emergencies while only one community within Kaduna State indicated the presence of community savings. Within some of the communities, it was mentioned that such community saving schemes had existed in the past but were no longer in existence. A respondent in one of the rural communities in Kano State remarked:

"This arrangement existed before in
our community and was facilitated by
an organization but it has now
collapsed."

In another community, it was reported that donations for maternal emergencies happen only when the need arises and not before the money is needed. One community leader from a rural community in Kaduna State pointed out:

"We don't donate money in advance. Rather when a situation arises we make contributions from community members to solve such problems."

In some communities, respondents reported that such contributions if they occur are typically for the less privileged and are arranged through donations in the mosques. An Imam from one of the communities in Kaduna State enthused:
"Yes we have mosque community savings which are used to assist pregnant women and other related works in the health center."

In addition, one community leader in Kano State remarked:
"No, we don't have community savings but when we realize that a household head is less privileged and is in need of money, we seek contributions for him through the mosque."

\section{Presence of transport for maternal emergencies}

Long distances between health facilities offering emergency obstetric health services and households of pregnant women, especially in rural communities, is strongly associated with the second delay to accessing emergency obstetric health care. The availability of adequate transport is a key factor influencing whether a pregnant woman experiencing a maternal emergency can reach a health facility on time. Possible means of transport to health facilities for pregnant women include friend/neighbour's vehicle, commercial vehicles within the community (i.e. taxis), motor cycle, animal drawn cart, a bicycle or by foot and very rarely a family vehicle. A quarter (4/16) of the rural communities surveyed report that they have some form of emergency transport arrangement in place to assist a woman experiencing a maternal obstetric emergency. For communities that have this type of emergency transport arrangement, community leaders indicate that these maybe supported by organizations, or simply exist as informal arrangements within communities. A community leader in a rural community in Kano State explained:

"Yes, we have this system which was
created by an organization. We have
commercial cars that are used to
convey pregnant women to the
hospital."

In some communities the emergency transport arrangement consists of community members who 
have vehicles and have volunteered to assist whenever there is need. A community leader in a rural community in Kaduna State remarked:

\begin{abstract}
"Yes, we do have this type of arrangement. If there is a pregnant woman who is in a state of labour, the [community] association gives money to a car owner for fuel or rents a car which is used to convey the patient to the hospital for safe delivery."
\end{abstract}

Another respondent narrated:

"Yes, we do have this arrangement. Some people in the community have agreed to transport pregnant women to the hospital whenever the need arises. If the household head is capable, he will fuel the car and if he isn't, the community will take care of fueling the car."

However the majority of rural communities which were surveyed do not have emergency transport arrangements to assist during obstetric emergencies. Pregnant women in these communities thus rely on 'ad hoc' arrangements when such situations arise. One community leader in Kano State said:

"No, we don't have this system, however, informal arrangements are made by the household head or his relative. If any member of the community has a vehicle, he is requested to help and he won't hesitate."

\section{Presence of blood donor groups}

Scarcity of blood contributes to delays in receiving appropriate obstetric care and is associated with the third delay to accessing obstetric emergency care. Spouses and relatives of pregnant women run the risk of not getting enough blood when a pregnant woman needs it the most. One way to address this is to ensure that within rural communities, there are individuals willing to donate blood or the existence of volunteer blood donor groups. Only one rural community among the sixteen communities in both states reported the presence of blood donor groups. The expectation of some community members is that any blood donation or blood transfusion system should be the responsibility of the local health facility; but some community leaders complained that nearby health facilities don't have such facilities. One community leader in Kaduna State explained:

"No, we don't have any group in the community in charge of blood donation because the (nearby) hospital does not have the facility for blood transfusion."

A respondent in another rural community in Kaduna state remarked:

"Actually we don't have (a system of donating blood) because apart from the community association which is responsible for the (nearby) hospital, we don't have any association for blood donation.'

Most community leaders expressed the view that blood donation was the responsibility of the household head or the relatives of the pregnant woman but if the need for blood is expressed during an emergency, community members can then donate blood. An Imam in one of the rural communities in Kano State pointed out:

\section{No we don't have (arrangements for blood donation); however, households or relatives volunteer on their own."}

A community leader of one of the rural communities in Kano State said:

"No formal group exists; however, when there is need, community members are usually enlightened to volunteer to donate blood, especially the youth."

\section{Presence of standing permission within households for women to visit health facilities during obstetric emergencies}

The decision to leave the house, depending on the presence or absence of standing permission is strongly associated with the first delay to accessing emergency obstetric health care. Most rural communities (11 of the 16 communities) in the two states reported that pregnant women still 
need some sort of permission to visit health facilities including during obstetric emergencies. This has a significant impact on whether a pregnant woman requiring care will get timely and appropriate obstetric care.

An Imam in one of the rural communities in Kano State remarked:

“...women need permission from their husbands and permissions are granted; even when the husband is not around, he can be reached through a mobile phone or his parents or a senior relative can give permission."

A community leader in Kaduna State replied with more reservation as follows:
“...permissions are granted to women, but some husbands usually don't give permission to their wives."

One community leader in Kano State insisted that permission was needed. He was clear that there is no standing permission (i.e. women need to obtain permission each time before leaving the house) within households in his community to visit health facilities during obstetric emergencies. He said:

".... women need permission from their husbands or parents and permission is granted. There is however no standing permission for maternal emergencies."

However, standing permission to visit a hospital does exist in some communities. A community leader from another rural community in Kano State indicated that there is standing permission existing and thus women do not need to obtain special permission to visit the health facility when the need arises. He replied:

“...women don't need permission from their husbands as there is already standing permission in place. You see people are very enlightened and they know the importance of going to the hospital."

Similarly a community leader of a rural community in Kaduna State remarked:

"...in fact we have general and specific permission given to women for that [a maternal emergency] because people in this community are aware of the dangers surrounding a pregnant woman when it comes to delivery."

\section{Discussion}

In many sub-Saharan African countries, maternal mortality tends to be high in rural areas where access to emergency obstetric care is limited by long distances to health facilities, lack of funds and socio-cultural norms. Women in remote rural communities have to travel long distances to reach a health facility for normal delivery or an emergency obstetric care health facility. Even when their pregnancies could be high risk pregnancies with maternal complications, the vast majority of rural women resort to giving birth at home ${ }^{5}$. The concept of the "three delays" has increased our understanding of how a number of issues around obstetric emergencies may lead to maternal deaths. The first and second delays are particularly significant as access to appropriate obstetric health care is still a major challenge in many low and middle income countries ${ }^{21,22}$. Rural pregnant women who lack reasonable access to health facilities offering 24/7 skilled birth delivery services need all the necessary support to ensure they receive timely maternal healthcare, especially if there is an obstetric emergency ${ }^{2}$. It is worrisome that only one rural community from this study reported the existence of all the key community maternal support systems. This is likely to have serious implications for pregnancy outcomes within these communities since this widespread lack of community maternal support systems is compounded by low knowledge levels of maternal danger signs and safe pregnancy practices among rural women as reported in another publication ${ }^{17}$.

From this baseline assessment, only a few rural communities in both States reported the existence of some sort of standing permission for pregnant women to visit a health facility for maternal healthcare including emergency obstetric care. The vast majority of rural community leaders indicated that women still need permission to access health care during pregnancy. This will inevitably have implications for overall pregnancy outcomes within these communities. It is important that community and religious leaders 
encourage community members to give standing permission within their households especially in rural communities to ensure that women who need to access health services can seek health services whenever the need arises without waiting for their husband's authorization.

Funds to support households experiencing a maternal obstetric emergency may come from relatives, friends or neighbours. However, the collective decision within communities to make savings for obstetric emergencies is influenced by a number of factors including the community's priorities and community members' perception of its necessity. Studies conducted in rural WestAfrican communities highlight in particular the cost of transport as well as cost for adequate health services as major obstacles to accessing emergency obstetric care services ${ }^{23}$. This makes it imperative that households with expectant mothers make the necessary financial savings during pregnancy periods. The findings from this survey indicate that only one out of the sixteen surveyed communities have community savings to carter for the needs of pregnant women. Most respondents indicate that it is only when the need arises that contributions are made to support a household in need. Even if funds are collected, the time taken to put together enough money contributes to delays in reaching and/or accessing emergency maternal healthcare. Moreover respondents in some communities mentioned that such money saving arrangements may have existed in the past but collapsed, thus indicating the need for proper sustainability strategies to be incorporated into financial schemes/strategies that support households with pregnant women. It is essential that community savings to support pregnant women be established (where absent) or strengthened (where existing) to ensure that financial barriers to accessing necessary obstetric care for pregnant women are eliminated or at least minimized. Possible avenues for this could be by specific monetary contributions through mosques or other religious or community associations. It is important that such funds are ring-fenced and kept specifically for the purposes of supporting households with pregnant women. This is especially crucial for families that may face financial challenges during obstetric emergencies.
Long distances between households in rural communities and health facilities as well as lack of adequate transport have been identified as barriers to accessing emergency obstetric care by pregnant women who are in need ${ }^{24}$. The findings of this assessment indicate that only four out of sixteen communities surveyed have some form of emergency transport in place to support pregnant women during obstetric emergencies. The responsibility of arranging for emergency transport should not be left entirely to the head of the household with an expectant mother. Community members should also be encouraged to volunteer their vehicles to assist in transporting expectant women when the need arises. Communities could also strengthen these arrangements by providing fuel to encourage such community members that volunteer their vehicles, time and effort. Another strategy to address this second delay is through forging partnerships between rural communities and transport unions; such schemes have been implemented in north-west Nigeria and have contributed to a reduction in maternal deaths ${ }^{25}$.

The availability and cost of obtaining blood during obstetric emergencies constitutes a major challenge for poor families which is compounded by the possible risk of death due to hemorrhage within hours. Even if the household of pregnant women ends up providing the required quantity of blood, the time spent outside the health facility in search of suitable blood donors may risk the survival of the pregnant woman ${ }^{5}$. Few low resource communities have hospitals with blood banks; thus for blood to be readily available, people must be willing to donate blood voluntarily whenever a transfusion is required. Cultural norms plus the fear of being tested positive for HIV during blood screening discourage people from donating blood; hence possible donors are reluctant to give blood, potentially creating a gap between demand for and supply of blood during some maternal emergencies ${ }^{26}$. Communities should establish volunteer blood donor groups while community and religious leaders should encourage blood donation among community members for health and maternal emergencies. In addition, State and Federal Governments need to establish and/or maintain blood banks within emergency obstetric health facilities. These 
measures are important because lack of adequate blood and the difficulties of blood transfusion are still key challenges in the management of obstetric emergencies in rural health facilities ${ }^{27,28}$.

The research findings and discussions in this paper are relevant to current discussions around efforts to attain the SDGs vis-à-vis maternal mortality reduction. Their relevance stands, even though the baseline assessment was conducted some years ago and the current situation in the rural communities involved in this research is likely to have improved significantly with the implementation of the safe motherhood intervention by the PATHS2 project. A key limitation of this research is the relatively small sample of rural communities used in the study but the findings and discussions are applicable to many low resource rural and urban communities in Nigeria as well as for other communities across the developing world.

\section{Conclusion}

Community maternal support systems may exist within rural communities in Nigeria and other developing countries. These support systems could be a community norm of standing permission within households for women to visit health facilities for maternal healthcare especially during pregnancy, community savings, emergency transport and volunteer blood donors. It is crucial that such support systems are strengthened, if existing, or established if non-existent within communities in order to provide the necessary support to pregnant women and reduce maternal mortality. Ensuring that these and other high impact interventions are implemented, especially within rural communities, will be crucial to attaining the SDGs.

Conflict of Interest: None declared.

\section{Acknowledgements}

This research received funding from the United Kingdom's Department for International development through the Partnership for Transforming Health Systems Phase 2 (PATHS2) project. The authors express their thanks to Safiyanu Mani and Abdulkadir Kabara for conducting community advocacy and the interviews with the community and religious leaders in the selected rural communities for the SMID baseline assessment. Special thanks are extended to Mustapha Tanko for transcribing the qualitative data from the SMID baseline assessment. The authors acknowledge PATHS2 senior management's support for the initiation, implementation and completion of this piece of research.

\section{Contribution of Authors}

EO and SBA jointly designed the study. EO led the data collection and data analysis processes. EO developed the first draft of the manuscript. SBA and IY critically revised the draft for substantial intellectual content. All authors read and approved the final manuscript.

\section{References}

1. Mbonye AK, Asimwe JB, Kabarangira J, Nanda G, Orinda V. Emergency obstetric care as the priority intervention to reduce maternal mortality in Uganda. Int J Gynaecol Obstet. 2007 Mar; 96(3): 220-5.

2. Aradeon, SB and Doctor, HV. Reducing rural maternal mortality and the equity gap in northern Nigeria: the public health evidence for the Community Communication Emergency Referral Strategy. International Journal of Women's Health 2016, 8: 7792; http://dx.doi.org/10.2147/IJWH .S94823.

3. Idris SH, Gwarzo UM, Shehu AU. Determinants of place of delivery among women in a semiurban settlement in Zaria, northern Nigeria. Ann Afr Med 2006; 5: 68-72.

4. Idris SH, Sambo MN, Ibrahim MS. Barriers to utilization of maternal health services in a semiurban community in northern Nigeria: The clients' perspective. Niger Med J 2013; 54: 27-32.

5. Thaddeus S, Maine D. Too far to walk: maternal mortality in context. Soc Sci Med. 1994 Apr; 38(8):1091-110.

6. Barnes-Josiah D, Myntti C, Augustin A. The "three delays" as a framework for examining maternal mortality in Haiti. Social Science \& Medicine 1998, 46(8): 981-993.

7. Combs Thorsen V, Sundby J, Malata A. Piecing together the maternal death puzzle through narratives: the three delays model revisited. PLoS One 2012; 7:12.

8. Okusanya BO, Okogbo FO, Momoh MM, Okogbenin SA and Abebe JO. Maternal mortality and delay: sociodemographic characteristics of maternal deaths with delay in Irrua, Nigeria. Niger J Med. 2007 Jan-Mar; 16(1):38-41.

9. Shah N, Hossain N, Shoaib R, Hussain A, Gillani R and 
Khan NH. Socio-demographic characteristics and the three delays of maternal mortality. $J$ Coll Physicians Surg Pak. 2009 Feb; 19(2): 95 - 8.

10. National Population Commission (NPC) (2014) ICF

Macro. Nigeria demographic and health survey 2013. Abuja, Nigeria: National Population Commission and ICF Macro.

11. Abimbola S, Okoli U, Olubajo O, Abdullahi MJ, Pate MA (2012) The Midwives Service Scheme in Nigeria. PLoS Med 9(5): e1001211. doi:10.1371/ journal.pmed.1001211.

12. Hogan M.C., Foreman K.J., Naghavi M., Ahn S.Y., Wang M., Makela S.M., Lopez A.D., Lozano R, Murray C. Maternal mortality for 181 countries, 1980- 2008: a systematic analysis of progress towards Millennium Development Goal 5. Lancet 2010, 375: 1609 -1623.

13. Adegoke AA, Lawoyin TO, Ogundeji MO, Thomson AM. A community based investigation of avoidable factors of maternal mortality in Nigeria: the pilot experience. Afr Health Sci. 2007;7(3):176-181.

14. Stephenson R, Tsui AO: Contextual influences on reproductive health service use in Uttar Pradesh, India. Stud Fam Plann 2002, 33(4):309-320.

15. Lassi ZS, Haider BA, Bhutta ZA. Community-based intervention packages for reducing maternal and neonatal morbidity and mortality and improving neonatal outcomes. Cochrane Database Syst Rev. 2010 Nov 10;(11): CD007754. doi: 10.1002/1465 1858. CD0 0775 4.pub2.

16. Costello A. Reducing maternal and neonatal mortality in the poorest communities. BMJ 2004; 329: 1166.

17. Okereke E, Aradeon S, Akerele A, Tanko M, Yisa I, Obonyo B. . Knowledge of safe motherhood among women in rural communities in northern Nigeria: implications for maternal mortality reduction. Reproductive Health 2013 10:57.

18. National Population Commission (NPC) [Nigeria]: Final Results of the 2006 National Population and Housing Census of Nigeria. Abuja, Nigeria: National Population Commission; 2009.

19. National Population Commission (NPC) [Nigeria]: Nigeria Demographic and Health Survey 2008. Abuja, Nigeria: National Population Commission and ICT Macro; 2009.

20. Wolf M, Abubakar A, Tsui S, Williamson NE: Child spacing attitudes in Northern Nigeria. Arlington, VI: FHI; 2008.

21. Mbaruku G, Roosmalen J, Kimondo I, Bilango F, and Bergstr"om S, "Perinatal audit using the 3-delays model in western Tanzania," International Journal of Gynecology \& Obstetrics, vol. 106, no. 6, pp. 8588, 2009.

22. Crowe S, Utley M, Costello A, Page C. How many births in sub-Saharan Africa and South Asia will not be attended by a skilled birth attendant between 2011 and 2015? BMC Pregnancy Childbirth. 2012; 12: 4.

23. The Prevention of Maternal Mortality Network, "Barriers to treatment of obstetric emergencies in rural communities of West Africa," Studies in Family Planning, vol. 23, pp. 279-291, 1992.

24. Ensor T and Cooper S, "Overcoming barriers to health service access: influencing the demand side," Health Policy and Planning, vol. 19, no. 2, pp. 6979, 2004.

25. Shehu D, Ikeh A, and Kuna M, "Mobilizing transport for obstetric emergencies in North-west Nigeria," International Journal of Gynecology \& Obstetrics, vol. 59, pp. S173-S180, 1997.

26. Jammeh A, Sundby J, Vangen S. Barriers to emergency obstetric care services in perinatal deaths in rural gambia: a qualitative in-depth interview study. ISRN Obstet Gynecol. 2011; 2011:981096.

27. WHO, Universal Access to Safe Blood Transfusion, World Health Organization, Geneva, Switzerland, 2008.

28. Sundby J, Vangen S and Cham M. "Maternal mortality in the rural Gambia, a qualitative study on access to emergency obstetric care," Reproductive Health, vol. 2, no. 1, 2005.

29. JHPIEGO and MNH Programme, Monitoring Birth Preparedness and Complication Readiness: Tools and Indicators for Maternal and Newborn Health, JHPIEGO, Baltimore, Md, USA, $4^{\text {th }}$ edition, 2004.

30. Gage A.J, "Barriers to the utilization of maternal health care in rural Mali," Social Science and Medicine, vol. 65 , no. 8, pp. 1666-1682, 2007. 